\title{
E-Cloud: A Solution towards E-Waste Management for Educational Institutions
}

\author{
Ritu Singhal, Archana Singhal, Varun Sharma, Saachi
}

\begin{abstract}
In the era of rapidly advancing frontiers of science and technical innovations over the recent years, the generations of electronic items have remarkably increased. Due to the globalization and the upgradations, electronic waste (e-waste) is growing at a compound annual growth rate of about $30 \%$ in the country. The issue has raised an alarming situation in the form of several health and environmental hazards like land, water and air pollution, depletion of non-renewable resources and loss of precious elements. Increasing levels of $\mathrm{CO}_{2}$ emissions in the environment has severely affected the geographic conditions as well. The proposed work includes an e-waste survey carried out under the auspices of Indraprastha College for Women, University of Delhi to gather information for spreading awareness about $e$-waste generation and its disposal. The present study on e-waste disposal and recycling includes both quantitative and qualitative approaches, along with a series of compiled results. The findings in the survey regarding the health hazards, environmental impacts, and existing disposal practices would be helpful not only to the country but will also be beneficial at the global level. To get an insight regarding the issue, a pilot survey was conducted prior to launching the final one. The variations in the responses of the pilot survey and suggestions by the corresponding respondents were of immense help in creating an improved version of the final survey. Based on the survey analysis, the authors have further proposed a cloud based model for the educational organizations for e-waste reduction for the effective and efficient utilization of resources. The proposed solution would be a mile stone in contribution towards the reduction of carbon footprint and e-waste generation at the global level.
\end{abstract}

Index Terms: E-cloud, Electronic waste, E-waste management, E-resource, Cloud Computing, Green Computing, Virtualization

\section{INTRODUCTION}

Environmental protection is one of the major concerns in the contemporary world. In this unstoppable race of success and greed, it seems like humans have got the license to exploit nature in one way or the other, ignoring the fact that everything has a payback. People are keen to have a luxurious lifestyle and are highly dependent on e-resources for most of

Revised Manuscript Received on July 22, 2019.

Ritu Singhal, I.P. College for Women, University of Delhi, Delhi, India. Archana Singhal, I.P. College for Women, University of Delhi, Delhi, India. Varun Sharma, I.P. College for Women, University of Delhi, Delhi, India. Saachi, I.P. College for Women, University of Delhi, Delhi, India. their work, be it a household chore or an extremely tedious work at an institution. But this high dependency has led to the generation of e-waste. E-waste refers the waste generated due to the discarded or non-usable e-waste products. The computers, printers, routers, wires, memory devices, and batteries gradually fall into the category of e-waste.

Electrical and Electronics Equipment (EEE) have generally made life easy and convenient because of their efficiency and time saving in application. Unfortunately, with the rapid development of electronic industry, the continuous upgrading of electronic products leads to the bulk of electronic waste. Several studies have been conducted to understand and analyze the impacts of e-waste on the surroundings.

The Associated Chambers of Commerce and Industry of India (ASSOCHAM) estimated that e-waste generation was 1.8 million metric tons (MT) per annum in 2016 and would reach 5.2 million metric tons per annum by 2020 [1]. Electronic waste has become the fastest growing garbage in today's world. Most developed countries have begun to pay attention on the electronic waste recycling and disposal and have started establishing a suitable system of electronic waste recycling [2]

The Water Research Institute of CSIR has also called for a ban on what it calls "primitive recycling of e-wastes". The study revealed that carcinogenic compounds are released into the atmosphere during the burning of e-waste to retrieve copper and other materials [3].

In the same line of concern, the government of India has also passed a law on e-waste management based on the Extended Producer Responsibility (EPR), which aims for the eco-friendly management of the e-waste product in final stages of the life. However, it did not set collection targets. Thus, this law was amended three years ago in 2016 in which a new arrangement entitled, 'Producer Responsibility Organization' (PRO) has been introduced to strengthen EPR [4].

The government has also undertaken awareness measures in this direction. The Ministry of Electronics and Information Technology has also initiated an E-waste Awareness programme under Digital India Campaign, along with industry associations from 2015, to create awareness among the public about the hazards of e-waste recycling by the unorganized sector, and to 
educate them about alternate methods of disposing of their e-waste.

The programme stresses on the need for adopting environmentally friendly e-waste recycling practices. The general public is also encouraged to participate in 'Swachh Digital Bharat', by giving their e-waste to authorized recyclers only [5].

Cognizance regarding e-resource management, optimization of resources and proper disposal of e-waste are the emerging concerns of the recent times. In spite of the government initiatives, still there is a need to make efforts at the personal level on continuous basis. Starting at the individual level and spreading the movement to various organizations, then within the society and finally to the whole country will gain the desired results. Now-a-days even intellectuals and researchers are paying attention to this problem along with analyzing the current scenario.

The authors of this paper have not only conducted an e-waste survey to make people realize about the harmful impacts of e-waste but also proposed an e-cloud model as a solution to the problem for the educational institutions.

Rest of the paper is organized as follows- Section 2 outlines the existing work done by various researchers which reveals the different viewpoints, opinions and different arenas of research. Section 3 discusses the proposed approach by the authors which consists of the methodology of the research, the two phases of survey analysis and the detail of the proposed model. The last section concludes the paper.

\section{LITERATURE REVIEW}

Various research papers from past a decade has also been published which discuss about the awareness factor and concerns regarding e-waste management, Unfortunately the research has been limited to a particular organization or area of concern which may not depict the reality as a whole. The authors in [6] have selected XI standard students of Anand city in the academic year 2010-11 using random sampling technique, whereas the population of the present survey is the students, the non- teaching and the teaching staff of the Delhi University and the other various institutions. The present work also aims for the varied categorical analysis based on the different age groups, academic and social background. Thus, it depicts a broader view of opinions and perspective.

Further, a paper [7] presents a synopsis of toxic substances present in e-waste, their potential environmental and human health impacts together with management strategies currently being used in certain countries. In the same line of research, authors [8] in their paper 'An innovative approach of e-waste issues solving' presented some detailed solutions to tackle the issue. Authors in the other paper [9] explained that the disposal of e-waste is a particular problem faced in many regions across the globe. Adding further in the list, authors in [10] briefly elaborated that why e-waste management is a challenge to public health in India.

Providing some technological solutions, authors in their paper [11] have focused on the reduction of e-waste through virtualization to save all over expenditures on hardware resources whereas the present work by the author has embedded a model in the educational domain and would establish the foundation of the cloud computing which itself revolves around the core concept of virtualization.

In reference to paper [12], an Audio repository application developed for helping visually impaired students using cloud platform, the authors claimed that the cloud computing is a boon, It not only lowers the investment cost of resources like storage and speed, but also removes physical barriers.

Authors in their paper [13] proposed a generic cloud model for resource provisioning to improve conventional education system. The importance of cloud computing technology in the basic education system has been justified by including latest tool as resources in cost effective manner. The model not only works on the issue of affordability in education sector, but also reduces the purchase of electronic resources thereby reducing the production of e-waste. Institutes having limited budget are unable to afford huge amount for infrastructure, thus they can be provisioned by the cloud providers according to the number of resources and time duration with pay per usage model. It also controls the generation of e-waste as the equipment's involved in creation of high infrastructure also reduces. Authors of present paper have considered this generic model as base and further enhanced it to use as one of the solutions to reduce the generation of e-waste and carbon footprint. In the continuity of the discussed aspects, the next section will describe the proposed approach in detail.

\section{PROPOSED APPROACH}

The proposed work has been carried out in two phases. In the first phase, a survey has been conducted to study the awareness regarding e-waste materials, its impact on environment and human beings and the issues of e-waste disposal.

In the second phase, some solutions have been suggested that can reduce the requirement of electronic resources in educational institutes and universities leading to reduction in e-waste generation. An E-cloud model has also been proposed by the author. This model would be an asset to the educational organizations which will help in e-waste reduction using current trends in technology.

These two phases are discussed in detail in the next section.

\section{A. Phase I}

In the first phase, data regarding the estimated growth rates of the global electronic industry versus the generation of e-waste were collected and its impact on the surroundings and the human beings were studied. 
Then, the questionnaire was made comprising of four sections. The sections include the issues starting from the awareness amongst the youth to the disposal and management of e-waste. The questions in these sections were framed in such a manner so that the students should start familiarizing themselves with the subject and hence, could provide us an honest opinion.

The next stage of this phase comprises of conducting a pilot survey for collecting the valuable feedback and responses regarding the questionnaire from the respondents of different departments. Since the perspective and opinions varies from person to person indulged in a particular field, the variations received in the responses and the suggestions proved to be a boon in framing the final survey.

The final survey included the responses of students, teaching and non-teaching staff of Indraprastha College for Women. To study the variations in the responses received, the survey was then expanded to include other colleges and institutions. The responses for the questions asked in the survey were then analyzed for proposing solutions to this problem. This analysis has been presented in detail in the next section.

\section{Survey Analysis-}

Since the present survey has been undertaken with the purpose of making people aware about "E-Waste awareness and Solutions", it includes questions like- Do you know what e-waste is? Have you ever wondered what happens to your damaged phones, useless batteries and earphones? Do they land in your dustbin or at a recycling center? What negative impacts do they have on your health and environment?

A total of 900 responses were recorded. The analysis of the responses were observed and used to suggest some solutions for tackling the issue and hence to create a healthy and safe environment.

The brief study of the responses obtained is described belowIn response to the question about the factors responsible for the increase in the usage of electronic devices, about $71.8 \%$ of the population was correctly able to answer as shown in figure 3.1 below. Hence, it can be concluded the majority of students are aware that exemption from manual work, technology advancement and globalization has led to the tremendous growth of the production of electronic devices.

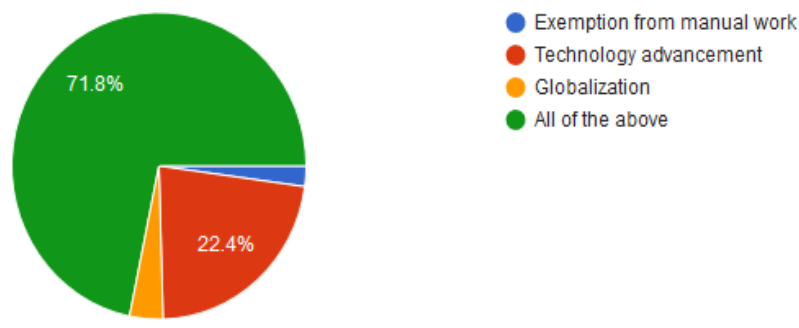

Fig 3.1 Factors responsible for increase in the usage of

\section{electronic devices}

To the question posed by the researcher about the electronic devices available in your institution, $93.7 \%$ of the people said that laptops, desktops, printers and projectors are commonly used in their organization as shown in figure 3.2, while in another question surprisingly only about $45.9 \%$ of them were not able to identify that the networking and the connecting devices also constitute a large fraction of e-waste, in their institution as shown in figure 3.3.
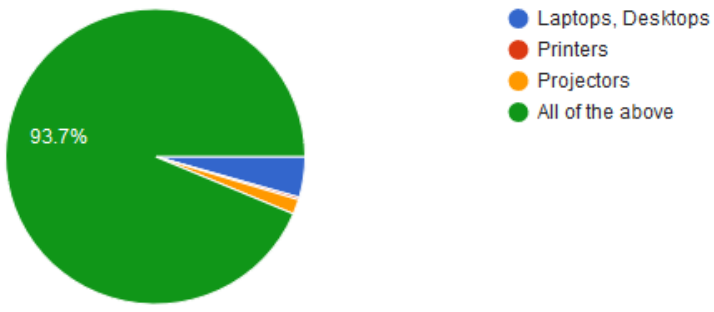

Fig 3.2 Electronic devices available in an organization

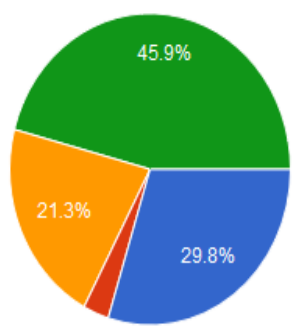

Local Area Network (LAN)

- Metropolitan Area Network (MAN) Wireless networking

Can't say

Fig 3.3 Connectivity of resources in ICT in an organization

In the next question, the respondents were asked about their participation in a discussion or a session on Electronic Waste Management before? The results to this question were quite shocking since only $42 \%$ of the people answered yes, which reflects that they identify this issue worth to acknowledge or handle.

It can be clearly observed from the figure 3.4 that the requirement of spreading awareness by increasing in the number of seminars, advertisements, indicators and group discussions about the hazards of e-waste, its impact on human beings and environment and the issues regarding e-waste disposal.

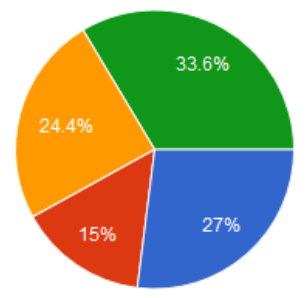

Fig 3.4 Participation of students

Published By:
Yes, at my College/School/Locality Yes, discussed with my friends No, but watched on TV - Never

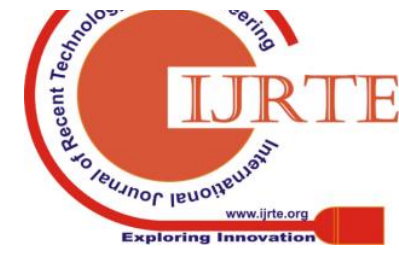




\section{E-Cloud: A Solution towards E-Waste Management for Educational Institutions}

in various e-waste discussions

The responses regarding the next question about the health hazards which can be caused by e-waste on human body were quite impressive since $79.4 \%$ of the people have correctly identified all the options stating that indeed it causes damage to DNA, have severe impact on heart and lungs and is responsible for the improper functioning of immune, nervous and reproductive system as shown in figure 3.5.
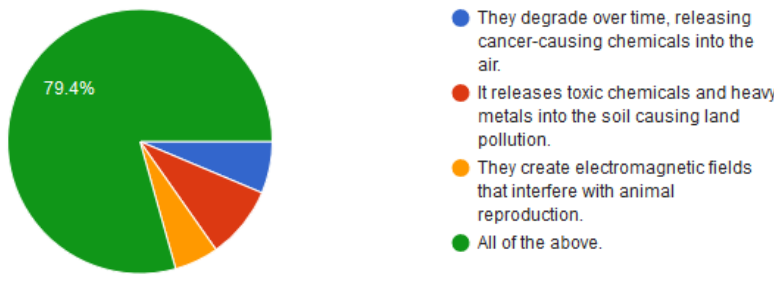

Fig 3.5 Health hazards caused by -waste

Further, another important question which depicts that "what people does with the working electronic products that they are not using anymore and with the damaged electronic product that are no longer useful for them" was included. So, analyzing the responses it can be seen from figure 3.6 that about $47.8 \%$ of the people sell the working electronic product on the second-hand basis. That is a good practice since the items could be then reused and leads to the sustainability goals. About $27 \%$ of them put it into storage which is not obviously a good option to go for since after a certain point of time, their life span gets over and consequently it turns into e-waste. About $14.2 \%$ of the people give the electronic product away for free, considering it for a social cause and $11 \%$ of them strip for spare parts and materials which may not be a considerable option because the common man doesn't know exactly what to do with which part of the e-resource product. Hence, it may lead to improper utilization of e-resources.
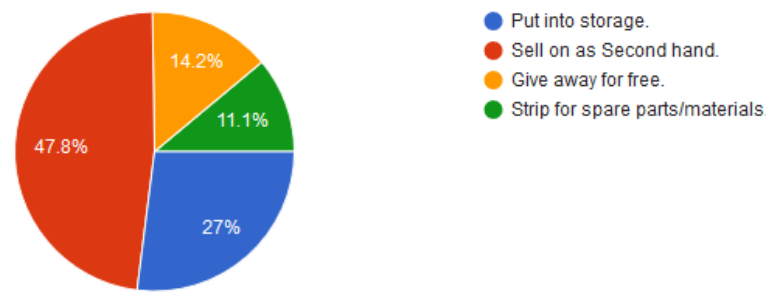

Fig 3.6 Handling of the working electronic products not using anymore

For the next question, the survey also reveals that $47.6 \%$ of the people sell the damaged product to the waste picker or give it away to a collection center and a fraction of people about $14 \%$ check the user manual for their safe disposal. And that is the best way to go for since each type of electronic equipment has its own impacts in accordance with the material it is made up of and thus have variations in its disposal methods. Any discrepancy in handling the product may lead to severe impacts. This option would not only provide you with the information about the constituents in the product but would also help to keep the environment and surroundings clean, green and safe. About $26 \%$ of the population give the no longer useful product to a collection center for recycling and $12.3 \%$ throw the product into the dustbin due to lack of awareness or knowledge as shown in figure 3.7.

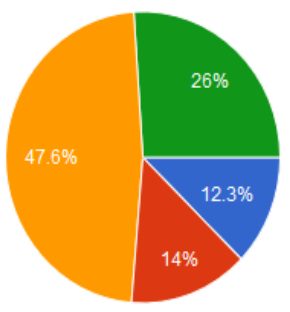

Throw them in the dustbin

- Check its User Manual for their safe disposal

Sell it to a waste picker or to the second-hand market

- Give it away to a collection centre for recycling

Fig 3.7 Handling of the damaged electronic product not suitable for use

To the question posed by the author about what do you think is the present scenario of Electronic Waste Management \& Disposal in the world? Approximately $35.2 \%$ of the population said that the issues and problems regarding e-waste can be controlled while $35.9 \%$ of them said that it is out of control. $27.3 \%$ of the population has no idea about the present scenario. Even if there is a minor difference in percentage of the first two categories, the figure clarifies an important aspect of the human behavior of willingness to overcome the issue, opting solutions and working on it.

Only $1.6 \%$ of the people believe that the situation is under control as given below in figure 3.8 .
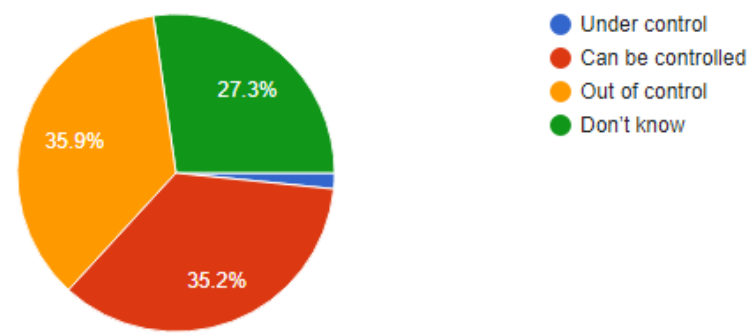

Fig 3.8 Present scenario of e-Waste Management \& Disposal in the world

The answer to the question about the knowledge of any e-waste collection center and recycling plants was extremely disappointing. Majority of the population about 76\% don't know about any collection center or recycling plants in their areas. Very low fraction of the people i.e. $24 \%$ knows about them. The figure 3.9 depicts that there is a need to make people aware of their neighboring recycling centers.

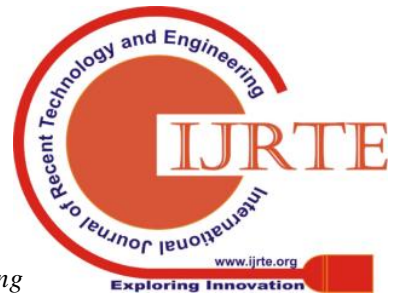

\& Sciences Publication 


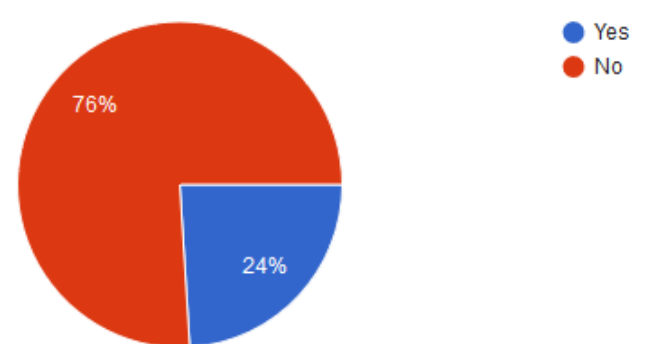

Fig 3.9 The knowledge about E-waste collection center or recycling plants

Based on the feedback of the conducted survey, the author has proposed solutions for e-waste reduction strategy for educational institutions which has been described in detail in phase II.

\section{B. Phase II}

It can be easily made out from the survey that there is a need to control this sudden increase in the generation of e-waste. Hence, immediate steps should be taken to find the cure to this problem. Thus, in this phase author have suggested various solutions and finally a model has been presented that can be implemented in the educational domain. It is a sustainable approach in the direction of e-waste reduction.

For picking up an institution in the educational domain, we have centralized universities, colleges, departments and distance learning across these universities. Stepping one level down, there are separate administrative blocks, Labs equipped with different e-resource systems, ICT centers and extremely armed accounts and management departments within these institutions. The smooth functioning of these facilities can't be even imagined without electrical and electronics support. So, this is the level where electronic resources come into picture and it has strengthened the working from the basic attendance and assessment procedures to the labs, timetable and co-curriculum design.

\section{Solutions to reduce e-waste in Educational Institutions-}

The present section will describe the solutions for the reduction of e-waste in the educational domain. It will further discuss the model proposed by the authors in detail.

\section{Optimization of resources through Efficient Lab Time table/ Co-curriculum Design}

The universities should design the semester syllabus in such a way that the same lab resources can be used for the whole year. Just for an example, if Bachelor of Science course involves both electronic and computer science labs, then these subjects should be taught in different semesters. For the other way around, if the department of computer science and mathematics offers the same generic elective subjects in their curriculum and involves lab hours, then these subjects should be taught in the departments in different semesters so that the effective hardware and management cost should be low and the resources could be fully utilized during their life span. In this way, the optimization of resources and their proper utilization would lead to the reduction of e-waste.

\section{Client Server Model V/s Stand Alone Systems}

Client Server Model is a technology in which the client process request services from the server process. The request and response process between server and clients are guaranteed through a network. But with the passage of time, the evolutionary shift from the thin client to the standard PC's has transformed the world of technology and globalization. These modern workspace managers or shall we say desktops and personal computers offer full functionality and performance with easy to handle and versatile capabilities.

However, given a thought they came with more hardware and software functionalities which are likely to get outdated in the short span if not utilized properly. Now, considering the issue in fully functional and largely armed organizations, the picture would become clearer in regard with the capital expenditure and the electronic waste generated. The implementation of client server model in these organizations will maintain its economy and also help in reducing the carbon footprint.

This would lead to the proper utilization of resources without necessarily buying them and would effectively save the amount spent on buying these resources as well.

\section{Public Cloud Based Virtual Desktop Environment}

For high end research in the universities and colleges, the universities can hire resources from public cloud instead of buying the infrastructure for short period for carrying out the specialized research work. Big universities manages many colleges under them, Instead of setting up labs with latest configurable machines at every college, a private cloud can be setup and all college can be equipped with thin clients or minimal required infrastructure.

Keeping these points into consideration, the author has proposed a model named as "E-Cloud Model" that would compile the above suggested solutions in one framework. In this way, it will be more economical and eco-friendlier step as well as lead us in the direction of energy efficient green computing. This model has been discussed in detail in the next section.

\section{The E-cloud Model}

Undoubtedly, Educational organizations need computational power as well technological supporting equipment for carrying out various procedures. Thus, they need a lot of hardware as well as software as per their requirement and efficiency of the systems. Correspondingly, the faculty, the staff and the students were also to be provided with these e-resource facilities for different applications. But after a span of time these 
electronic devices get outdated due the up-gradations in the technology. This leads to the generation of large amount of e-waste within these organizations. Any discrepancy in handling this e-waste would result in severe concerns. The proposed model in the long run will assist towards efficient utilization of resources and making environment clean, green and safe.

The architecture of the proposed model as shown in figure 3.10 consists of five layers as described below-

The first layer of the Cloud architecture includes datacenters that constitutes essential parts of cloud computing environment. In a single datacenter generally a number of virtual servers run at any instance of time, hosting many tasks and at the same time the cloud system keeps receiving the batches of task requests. It is the reservoir of dynamic and scalable resources.

The second layer consists of services required by the consumer.

It includes three kinds of services infrastructure service, platform service and application software service.

The third layer is the main integral part of this architecture. It deals with the management of the cloud and handles the accounting, billing, auditing, reporting, load balancing and virtualization. It would allocate the resources to the consumer as per their requirement and in required combination. This would be done after verifying the consumer's identity. Also, the user can pay as per on demand basis.

The fourth layer verifies the identity of the consumer. Different access rights are given to different users due to privacy and security issues. Unauthorized use of resources is not allowed. The cloud provider would set the access rights in accordance with different consumer levels.

The last layer is cloud consumers. The consumers would summit their request for the resources and would get them allocated from the cloud provider.

The author suggests the centralized universities to have their own cloud according to their requirements. Small Universities, if can't afford for the same, can rent their resources or even tie up from central universities with cloud facilities. The working of the model is described as follows.

\section{Working of the Proposed Model-}

The model personifies the three important roles: Cloud Provider, Cloud Consumer and Cloud Developer.

In the present scenario Cloud provider is the University and consumers are various departments and colleges under Universities. The consumers can request regarding the infrastructure, platform and application services. The infrastructure services include storage, CPU access time, memory and networking. Platform dependent services include operating system, virtual classroom, virtual labs, application development and testing tools. Application software services include all applications for direct usage. The decision-making power regarding the price estimates lies in the hands of provider. Cloud Developer will manage the development and deployment of services like virtual classrooms, virtual labs, online admission process, examination procedures, student/faculty/staff information etc.

The next section will discuss about the superiority of the proposed model over other architecture.

\section{Eminence of the Proposed Model-}

The model has many advantages in comparison to other environments. It has various features that would enable an organization to achieve more scalability. As hardware resources are shared at university level, It will reduce the hardware, software and maintenance cost at the user level and only the basic facilities are required to access cloud through internet. Since an organization also requires a huge amount of storage space to store reservoirs of information, the cloud platform would be the best option to go for. Subsequently, it is an excellent framework for virtual classrooms, virtual labs, online admission and examination process, online student information system also. It is a platform for pay as per use and can be standardized as per university norms. The colleges would ask for the resources from the cloud provider according to educational curriculum and would pay as per use. This would lead to the proper utilization of resources without necessarily buying them and would effectively save the amount spent on buying these resources as well. 


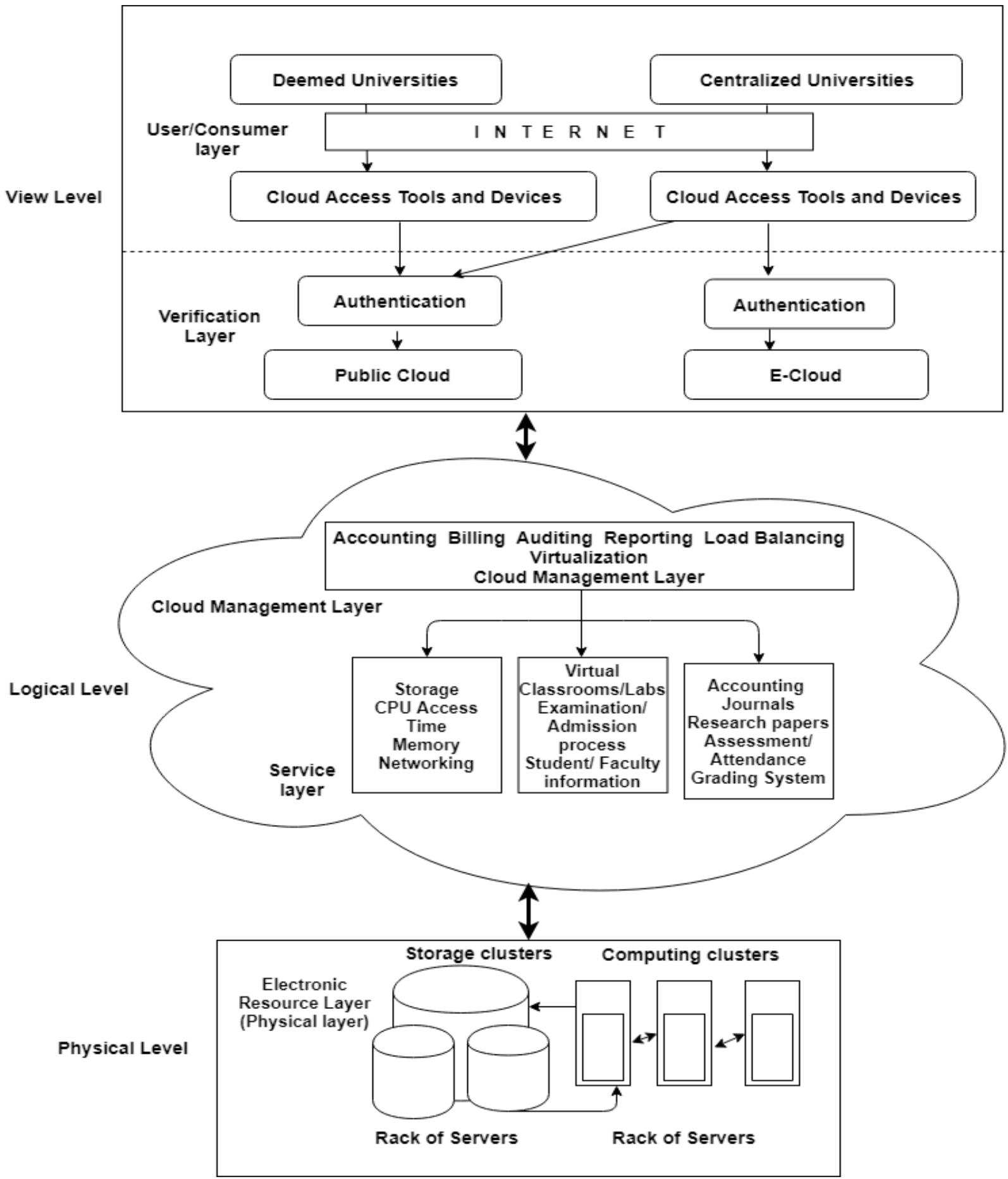

Fig 3.10 E-cloud Model 
Secondly, the colleges of the same university could share their resources amongst them since the cloud provider is the same university.

In this way, the amount of e-resources production would decrease by at least half which would result in less e-waste generation. Thirdly, the author also suggests the universities to design the syllabus for both even and odd semesters in such a way that lab resources can be shared.

The model would tend to reduce the production of e-resources through cloud technology further leading to the reduction of e-waste generation. Suppose a university had a bulk of hardware and supporting electronic equipment for their functioning and educational purposes. The labs for the different departments are loaded with enormous facilities for the students. But the utilization of the resources doesn't reach even 50\%. As a result, with the passage of time, the life span of these resources reduces turning them into e-waste. Even the other electronic devices, the AC's and the networking equipment's like switches, hubs and wires also result into less efficient and non-workable resources. Hence, technically the institutions face major loses since a huge sum of economy is spent in maintaining and buying these resources.

The model will help in improving the education and working standards of the university. In the long run, it can be seen that the e-resources production can be reduced by implementing the proposed model which will result in less e-waste production.

The following section concludes the paper with future scope.

\section{CONCLUSION}

The problem of e-waste is one of the emerging concerns of the recent times. It has severe impacts on the surroundings and the living beings. The present study therefore, encompasses an e-waste survey analysis on the premises of the Indraprastha College for Women, Delhi University and in various other institutions to recognize e-waste hazards. The survey has depicted the variations in the viewpoints and perspectives of the population belonging to different age groups, academic and social backgrounds. The results of the survey show the lack of awareness among people regarding the subject of concern. It also depicts that there is a need to embark the knowledge of the recent technologies and e-resources amongst the youth through various seminars and workshops in the educational domain as well. Hence, on the basis of the observations in the survey, an e-waste reduction model namely 'E-cloud' has been proposed by the author as a solution for the educational institutions which act as a giant for the e-resource hub for their population. The organizations, with the implementation of this model, would not only become the ambassadors for the environmental protection but would also get an opportunity to appeal and indulge their students towards the sustainable use of resources. It would be even better if these organizations include this issue as an emerging concern in their educational curriculum which would pave the way towards sustainable technological practices.

\section{ACKNOWLEDGMENT}

The authors are grateful to Dr. Babli Moitra Saraf, Principal, Indraprastha College for Women, University of Delhi, for her valuable suggestions during the $\mathrm{E}$-waste survey campaign. The E-waste survey was conducted under the Science Society of the IP College and the College community has participated and made the awareness campaign a huge success.

\section{REFERENCES}

[1] https://www.statista.com/statistics/499891/projection-ewaste-generation-w orldwide/

[2] https://www.slideshare.net/ErnestoEmpig/technologies-for-sustainable-ewas te-management-solutions

[3] https://www.thehindu.com/sci-tech/energy-and-environment/what-about-ewaste/article24193081.ece

[4] https://meity.gov.in/content/awareness-programme-environmental-hazardselectronic-waste

[5] M. Sikdar, S. Vaniya, "The New Millennium and Emerging Concerns", International Journal of Scientific and Research Publications, Volume 4, Issue 2, February 2014 1, ISSN 2250-3153.

[6] https://www.myjoyonline.com/lifestyle/2017/march-16th/csir-pokes-actionagainst-burning-of-e-waste-at-agbogbloshie.php

[7] Kiddee, Peeranart, R. Naidu, and M. H. Wong. "Electronic waste management approaches: An overview" Waste management 33.5 (2013): 1237-1250.

[8] F. Veglio, I. Birloaga and I. D. Michelis, "An innovative approach for e-waste issues solving", International Journal of Waste Resources, 8th World Congress and Expo on Recycling,Berlin, Germany,June 2018 , E-ISSN: 2252-5211

[9] T.V. Ramachandra., K. Saira Varghese, "Environmentally sound options for e-waste management", Energy and Wetlands Group, Center for Ecological Sciences, Indian Institute of Science, Bangalore. Published by: Envis Journal of Human Settlements, March 2004.

[10] Monika, J. Kishore, "E-Waste Management: As a Challenge to Public Health in India", IJCM, Volume 35.

[11] S. Anwar, M. Ghaffar, F. Razzaq, B. Bibi, "E-waste reduction via virtualization in Green Computing", ASRJETS, ISSN: 2313-4402.

[12] R. Singhal, A. Singhal, M. Bhatnagar, and N. Malhotra. "Design of an Audio Repository for Blind and Visually Impaired: A Case Study." In Advanced Computing and Communication Technologies, pp. 77-85. Springer, Singapore, 2019.

[13] R. Singhal, A. Singhal, Sonia. "Towards a generic E-Cloud architecture for universities", IJWA 8.2 (2016), 36-43.

[14] M.D. J. Uddin, (Environment) "E-Waste Management", IOSR Journal of Mechanical and Civil Engineering (IOSRJMCE), ISSN: 2278-1684 Volume 2.

[15] https://en.wikipedia.org/wiki/Electronic_waste 
E-Cloud: A Solution towards E-Waste Management for Educational Institutions

\section{AUTHORS PROFILE}

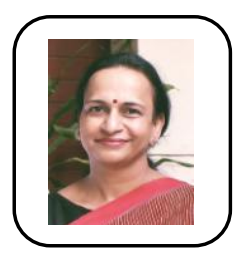

Ritu Singhal, Assistant Professor, Department of Computer Science, Indraprastha College for Women, University of Delhi, New Delhi. She is pursuing her PhD in Computer Science from University of Delhi, New Delhi. Her research area include Cloud Computing. She has publications in journals and International conferences.

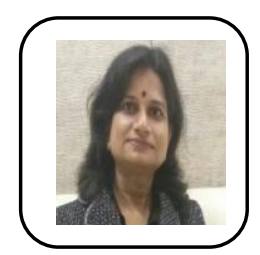

Dr. Archana Singhal is Associate Professor, Department of Computer Science, Indraprastha College for Women, University of Delhi, New Delhi. Her research areas include Natural Language Processing, Semantic Web, Cloud computing, Information Retrieval, Secure Software Systems. She has many publications to her credit in reputed journals and International conferences.

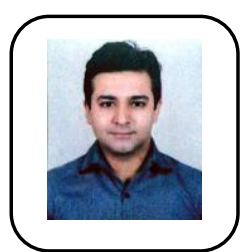

Varun Sharma is working as Senior Technical Assistant in Indraprastha College for Women, University of Delhi. He has completed his MCA from U.P. Technical University along with the CCNA certification. His research areas are E-resource management, Ethical Hacking, Wireless Technologies, and Networks.

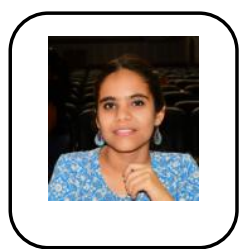

Saachi is pursuing B.Sc. Computer Science $(\mathrm{H})$ from Indraprastha College for Women, University of Delhi. Her area of interest includes Machine Learning and Advanced algorithms. 